Brief Report

\title{
Structural Modifications of 3-Triazeneindoles and Their Increased Activity Against Mycobacterium tuberculosis
}

\author{
Konstantin B. Majorov ${ }^{1}$, Boris V. Nikonenko ${ }^{1}$, Pavel Yu. Ivanov ${ }^{2}$, Lyudmila N. Telegina ${ }^{2}$, \\ Alexander S. Apt ${ }^{1, *}$ and Valeria S. Velezheva ${ }^{2}$ \\ 1 Central Research Institute for Tuberculosis, Moscow 107564, Russia; majorov@list.ru (K.B.M.); \\ boris.nikonenko52@gmail.com (B.V.N.) \\ 2 Institute for Element-Organic Chemistry Russian Academy of Sciences (INEOS RAS), Moscow 119334, \\ Russia; smushk@yandex.ru (P.Y.I.); larina@ineos.ac.ru (L.N.T.); vel@ineos.ac.ru (V.S.V.) \\ * Correspondence: alexapt0151@gmail.com; Tel.: +7-499-785-90-72
}

Academic Editors: Luisa Jordao and Ines Joao Received: 18 May 2020; Accepted: 18 June 2020; Published: 24 June 2020

\begin{abstract}
We synthesized 100 novel indole-based compounds with polyaza-functionalities, including 3-triazeneindoles, and tested their activity in vitro against laboratory M. tuberculosis $\mathrm{H} 37 \mathrm{Rv}$ and clinical izoniazid-resistant $\mathrm{CN}-40$ isolates, using gross and fine titration approaches. Here we present a few 3-triazeneindoles with the highest anti-mycobacterial activity. Introduction of short lipid tails into the 3-triazeneindole core additionally increased their activity against mycobacteria engulfed by murine macrophages. We also demonstrate that the compound TU112, one of the most active in our previous study, being not bioavailable after administration in mice per os, manifests prominent anti-mycobacterial activity after intravenous or aerosol delivery, as assessed by the mouse serum and lung supernatant titration assays.
\end{abstract}

Keywords: tuberculosis; drug candidates; 3-triazenoindoles

\section{Introduction}

There is an urgent need for novel anti-tuberculosis (TB) drugs active against multidrug resistant (MDR) and extensively drug-resistant (XDR) M. tuberculosis strains [1,2]. With few exceptions, current anti-mycobacterial drugs and compounds in clinical trials are aimed at well-established critical cell syntheses: wall, essential protein, and nucleic acids (reviewed in [3]). Given their central role in general biology, there is little doubt that the majority of ongoing TB drug studies continue targeting these biochemical pathways, although the search for alternative targets is intensive (e.g., see ref. $[4,5]$ ). However, as a recent example with five newly introduced TB drugs shows, the acquisition of resistance to any compound by mycobacteria is a matter only of a relatively short time [6], so the pipeline should always be full with new candidates.

In our previous study, we showed that replacing the amino group in 3-amino-2-ethoxycarbonyl indoles with three lined-up nitrogen atoms, i.e., the triazene group, results in the creation of 2-ethoxycar bonyl-3-triazeneindoles. Among more than 200 target-synthesized indole-based compounds, seven 3-triazenoindoles displayed a good level of in vitro activity (minimal inhibitory concentration (MIC) between 0.2 and $0.5 \mu \mathrm{g} / \mathrm{mL}$ ) against Mycobacterium tuberculosis strain $\mathrm{H} 37 \mathrm{Rv}$, isoniazid (INH)-resistant human isolate $\mathrm{CN}-40$, and Mycobacterium avium. The compound TU112 was additionally active against an artificially created dormant $M$. tuberculosis strain. These compounds showed high selectivity indexes (SI) for M. tuberculosis and M. avium in the infected mouse macrophage model [7].

To improve the efficacy and pharmacokinetic properties of the title products, we designed and synthesized 100 novel 3-N-substituted derivatives of indole-2-carboxylic acid. Here we present a few 
novel indole-based compounds, with higher levels of anti-tuberculosis activity, selected from a newly synthesized panel. The activity of selected compounds against intracellular M. tuberculosis was further increased by substitution of the ethyl ester $\mathrm{COOC}_{2} \mathrm{H}_{5}$ group, at the position 2 of the indole ring, with the short-chain 1-octanol-based lipid tail $\mathrm{COOC}_{8} \mathrm{H}_{17}$, an octyl ester group. In addition, we addressed the problem of the low bioavailability of the previously tested compound TU112 with a high level of anti-mycobacterial activity. To this end, we tested the anti-mycobacterial activity of (i) mouse sera obtained after intravenous administration of TU112, and (ii) lung homogenate supernatants obtained after TU112 inhalation.

\section{Results and Discussion}

The anti-mycobacterial performance of newly synthetized compounds is displayed in Table 1 in numerical order. Six compounds with the highest activity (MIC $=<0.021-0.4 \mu \mathrm{g} / \mathrm{mL}$ ) are highlighted in bold. Remarkably, MICs for the INH-resistant CN-40 strain were similar. The activity of some of these compounds is higher than of those described previously $[7,8]$, which makes these candidates attractive for further preclinical studies using a widely accepted algorithm [9].

Table 1. Anti-mycobacterial activity of new of 3-triazenoindoles (concentration range, $\mu \mathrm{g} / \mathrm{mL}) * * *$.

Against H37Rv


Table 1. Cont.

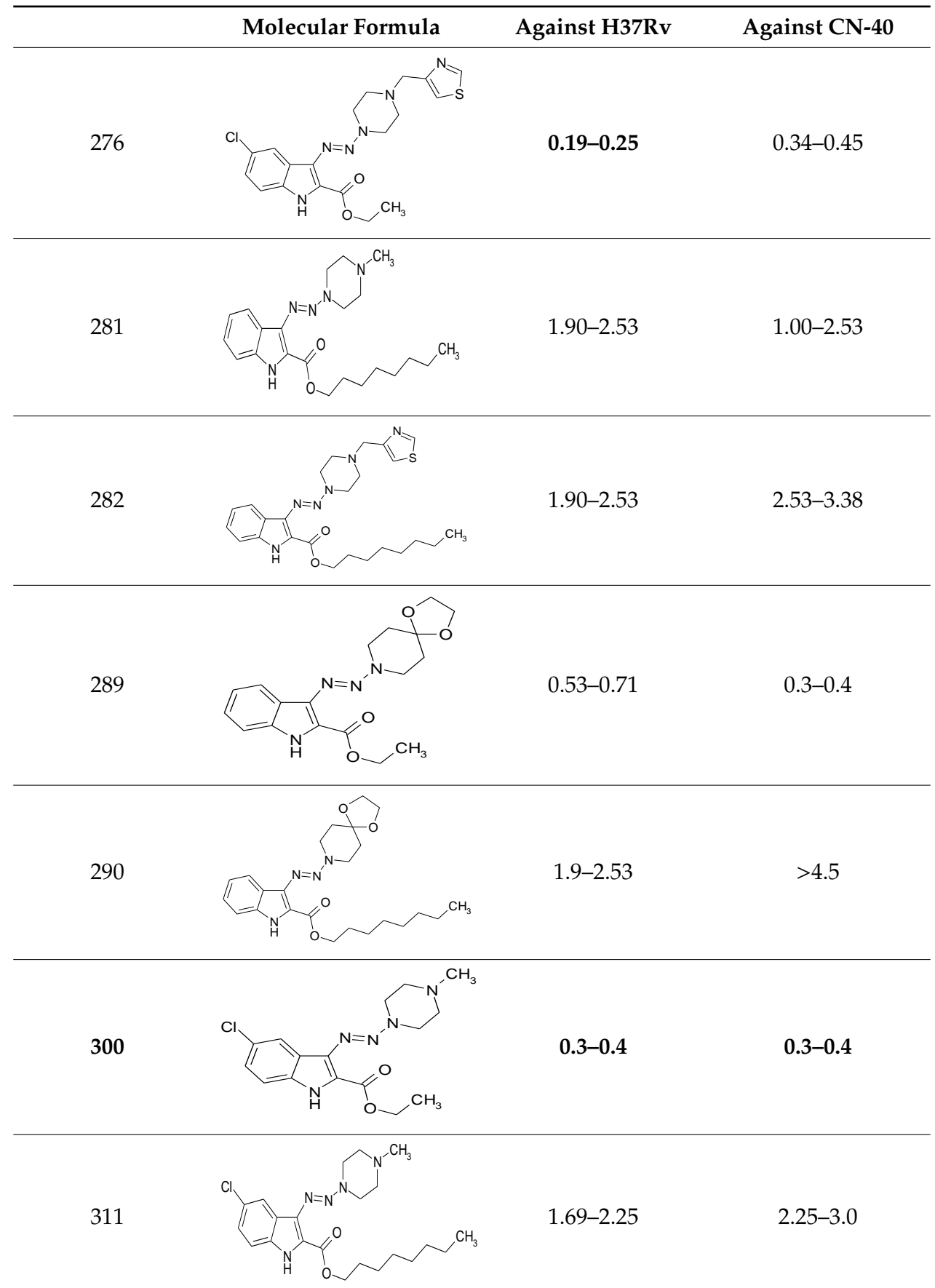

* MIC is displayed as the range between the lowest concentration for completely abrogating mycobacterial growth and the highest concentration at which the growth was discerned. ${ }^{* *}$ Approved Russian patent application \# 2019113030 "3-triazenoindoles active against mycobacteria", to be issued.

Considering chemical modifications that might increase the performance of previously established compounds, we assumed that the introduction of a hydrophobic tail at the position 2 of the indole nucleus would increase its permeability through the macrophage cell membrane, and thus improve its bactericidal activity against intracellular mycobacteria. Figure 1 and Table 2 display the results of the testing of such modified compounds, in comparison with the parental ones. Comparison of the original "ethanol esters" TU276 and TU112 with their 1-octanol modified "octanol esters" TU282 and TU281 demonstrated that the latter were $2-4$-fold more effective against macrophage-engulfed $M$. 
tuberculosis, despite the significant decrease of their activity against extracellular bacteria. 1-Octanol $\left[\mathrm{CH}_{3}\left(\mathrm{CH}_{2}\right)_{7} \mathrm{OH}\right]$ itself displayed no anti-mycobacterial activity $(\mathrm{MIC}>80 \mu \mathrm{g} / \mathrm{mL}$ ).

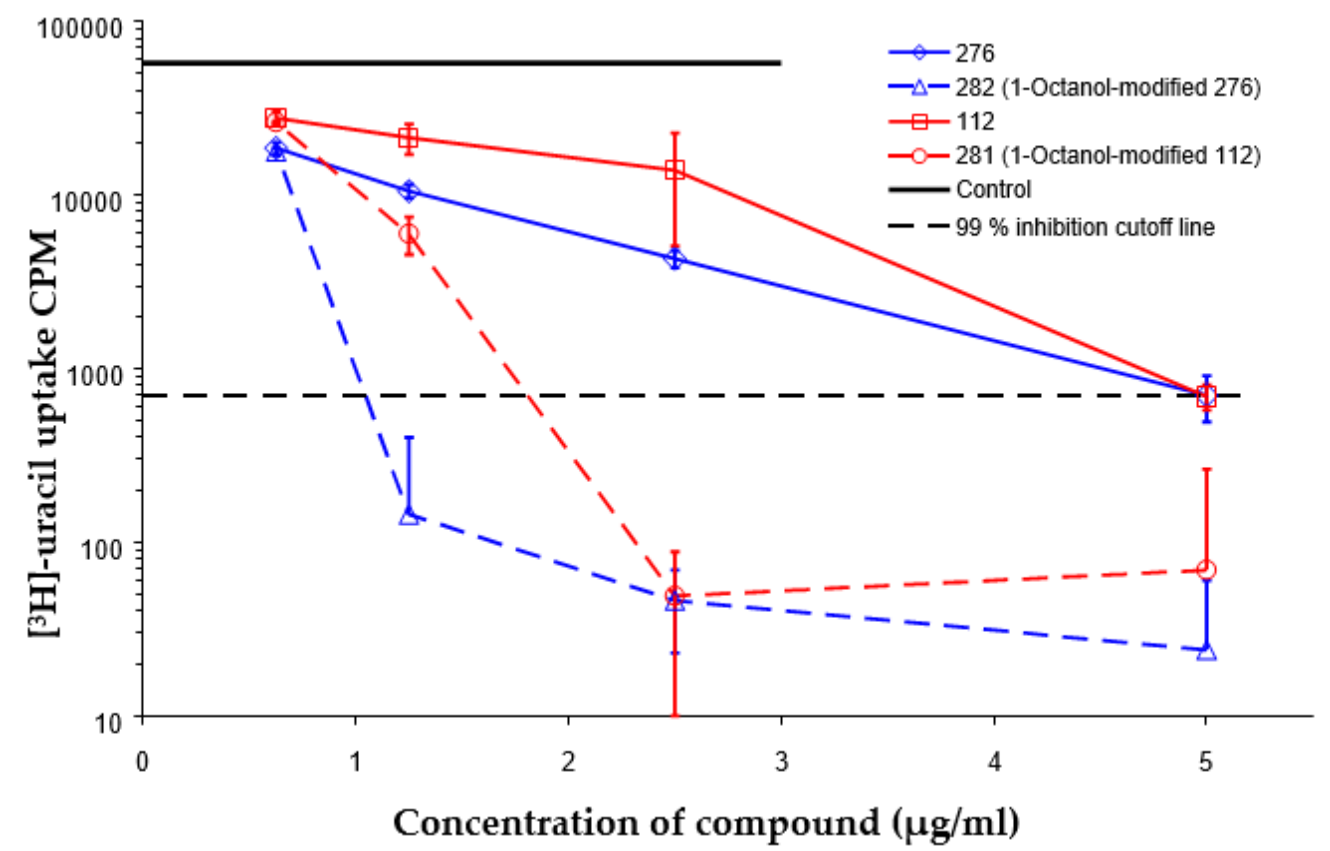

Figure 1. Inhibition of ${ }^{3}[\mathrm{H}]$-uracil uptake by intracellular mycobacteria. Results are expressed as medium counts per minute $(\mathrm{CPM} \pm \mathrm{SD})$ for triplets. Solid black line (control): the level of $\left[{ }^{3} \mathrm{H}\right]$-uracil uptake in the absence of compounds. Dashed line: the level of $99 \%$ inhibition compared to control samples.

Table 2. Introduction of octyl residues improves performance of 3-triazeneindoles against intracellular M. tuberculosis.

\begin{tabular}{ccccc}
\hline Compound & TU276 & TU282 * & TU112 & TU281 ** \\
\hline $\begin{array}{c}\text { MIC for intra-macrophage } \\
\text { mycobacteria } \\
(\mu \mathrm{g} / \mathrm{mL})\end{array}$ & 5.0 & 1.25 & 5.0 & 2.5 \\
\hline $\begin{array}{c}\text { MIC for free mycobacteria } \\
(\mu \mathrm{g} / \mathrm{mL})\end{array}$ & $0.19-0.25$ & $1.92-2.53$ & $0.19-0.25$ & $1.90-2.53$ \\
\hline \multicolumn{2}{c}{$* 1-$ Octanol-modified TU276. ${ }^{* *}$ 1-Octanol-modified TU112. }
\end{tabular}

These results suggest that the 1-Octanol-modified compounds behave like prodrugs, whose anti-mycobacterial activity restores and even increases inside the host cells [10].

Another problem that arose during our previous studies was the low bioavailability of the TU112 compound (the one with an appreciable in vitro anti-mycobacterial performance [7]). Assuming that its poor performance in vivo may be due to metabolic destruction after administration per os, we evaluated the in vitro anti-mycobacterial activity of sera and lung tissue homogenates obtained from mice that had received TU112, by, respectively, intravenous injection and inhalation. To this end, we used the inhibition titration assay, described in detail by Onajole et al. [11]. As shown in Table 3, the final dilution of mycobacteria-active sera from mice intravenously treated with TU112 was about an order of magnitude higher than that from the control mice. The final active dilution of lung homogenate supernatants from mice that received TU112 by inhalation was 8-fold higher than in controls. These results suggest that TU112 possess potential anti-mycobacterial activity in vivo. 
Table 3. Final dilutions of serum and lung homogenate samples providing inhibition of mycobacterial growth *.

\begin{tabular}{|c|c|c|c|c|c|c|}
\hline $\begin{array}{l}\text { Sera from } \\
\text { Intact Mice }\end{array}$ & \multicolumn{3}{|c|}{ Sera from TU112-Treated Mice } & $\begin{array}{c}\text { Serum from } \\
\text { INH-Treated } \\
\text { Mouse }\end{array}$ & $\begin{array}{l}\text { Lung Tissue } \\
\text { from Intact } \\
\text { Mice }\end{array}$ & $\begin{array}{c}\text { Lung Tissue from } \\
\text { TU112-Treated } \\
\text { Mice }\end{array}$ \\
\hline \multirow{2}{*}{$3.6 \pm 3.0$} & $15 \mathrm{~min}$ & $1 \mathrm{~h}$ & $4 \mathrm{~h}$ & \multirow{2}{*}{$243 \pm 172$} & \multirow{2}{*}{$2.0 \pm 1.4$} & \multirow{2}{*}{$17.6 \pm 8.7$} \\
\hline & $64 \pm 39$ & $70 \pm 35$ & $64 \pm 39$ & & & \\
\hline \multicolumn{4}{|c|}{ ANOVA, $p=0.017$} & & \multicolumn{2}{|c|}{ ANOVA, $p=0.0044$} \\
\hline
\end{tabular}

Taken together, our results indicate that 3-triazeneindoles represent a class of compounds with an impressive activity against virulent mycobacteria, and that their chemical modification with hydrophobic tails at the indole nucleus further improves their performance against intracellular mycobacteria. Now we are starting evaluation of their activity in vivo using several mouse TB models.

\section{Materials and Methods}

\subsection{Compounds Synthesis}

A series of new 1,1-dialkyl-3-[2-(ethoxycarbonyl) indol-3-yl]triazenes, "triazene ethyl esters", (ECIT), (TU214, 236, 250, 251, 276, 289, 300), as well as the previously described [7] compound TU112 (Table 1), incorporating N-methylpiperazine and related congeners, were synthesized as described earlier [12,13] by the $\mathrm{N}-\mathrm{N}$ cross coupling reactions of appropriate 2-ethoxycarbonyl-3-diazo-3H-indoles (ECDI), at a large excess (ratio $=1: 10$ ) of appropriate piperazines or diethanolamine. A set of new 1,1-dialkyl-3-[2-(octyloxycarbonyl) indol-3-yl]triazenes (TU 281, 282, 290, 311) "triazene octyl esters" (OCIT) were synthesized analogously by the $\mathrm{N}-\mathrm{N}$ cross coupling reactions of appropriate 2-octyloxycarbonyl-3-diazo-3H-indoles (OCDI) at a large excess (ratio $=1: 10)$ of appropriate piperazines. Reactions were continued until the diazo stretch band $(\sim 2100 \mathrm{~cm})$ disappeared. The yields of triazeneindoles were 30-90\%. Initial 2-octyloxycarbonyl indoles required for the synthesis of OCDI were obtained by the Fisher indole synthesis followed by alkaline hydrolysis and subsequent p-toluenesulfonic acid-catalyzed esterification of appropriate indole-2-carboxylic acids with 1-octanol, as described [14]. Chemical structures of compounds were supported by elemental analyses, ${ }^{1} \mathrm{H}-\mathrm{NMR}$, ${ }^{13} \mathrm{C}-\mathrm{NMR}$ and ESI-HRMS spectral data.

All chemicals were purchased from Sigma-Aldrich and ACROS Organics at the high purity grade and used without further purification. The yields refer to purified products and were not optimized. IR spectra were run as KBr disks on an IR-Fourier-spectrometer Magna 750 IR Nicolet. ${ }^{1} \mathrm{H}$ NMR $(300,400$ or $600 \mathrm{MHz})$ and ${ }^{13} \mathrm{C}$ NMR $(75,101$ or $151 \mathrm{MHz})$ spectra were recorded using Bruker Avance ${ }^{\mathrm{TM}}-300$, Bruker Avance ${ }^{\mathrm{TM}}-400$ or Bruker Avance ${ }^{\mathrm{TM}}-600$ spectrometers. Mass spectra were recorded using Finnigan LCQ Advantage for ESI, on a Finnigan LTQ FT Ultra for HRMS (ICR) and Finnigan Polaris Q for EI. Elemental analyses were performed at the Laboratory of Microanalysis of A. N. Nesmeyanov Institute of Organoelement Compounds, Moscow. Flash Column chromatography was performed using Silica gel Merck 60 (Merck, 230 mesh).

\subsection{Mycobacteria}

M. tuberculosis strain H37Rv, sub-strain Pasteur, and the clinical isoniazid-resistant M. tuberculosis isolate CN-40 from the collection of the Central Institute for Tuberculosis (Moscow, Russia), were maintained and prepared for in vitro studies exactly as previously described [15]. Briefly, $50 \mu \mathrm{L}$ from a thawed $10^{8} \mathrm{CFU} / \mathrm{mL}$ aliquot was added to $30 \mathrm{~mL}$ of Dubos broth base (BD) supplemented with $0.5 \%$ fatty acid-poor BSA (Calbiochem) and incubated for 2 weeks at $37^{\circ} \mathrm{C}$. The resulting suspension was washed two times at $3000 \mathrm{~g}, 20 \mathrm{~min}, 4^{\circ} \mathrm{C}$ with Ca- and Mg-free PBS containing $0.2 \mathrm{mM}$ EDTA and 
0.025\% Tween 80, re-suspended in PBS with $0.025 \%$ Tween 80 and filtered through a $5 \mu \mathrm{m}$-pore-size filter (Millipore) to remove clumps.

To estimate the CFU content in the filtrate, $20 \mu \mathrm{L}$ from each 5-fold serial dilution was plated onto Dubos agar (BD), and the total number of micro-colonies within the spot visible on the air-dried agar was calculated under an inverted microscope (200× magnification) after being cultured for 3 days at $37^{\circ} \mathrm{C}$. The bulk of the filtered culture was stored at $4{ }^{\circ} \mathrm{C}$, and it was found that no change in the CFU content occurred during this storage period.

\subsection{Animals}

Mice of the C57BL/6JCit (B6) inbred strain were kept under standard conditions in the Animal Facilities of the Central Institute of Tuberculosis (Cit), Moscow, in accordance with the guidelines of the Russian Ministry of Health № 755 and the NIH Office of Laboratory Animal Welfare Assurance № A5502-11. Food and water were provided ad libitum. All experimental procedures were approved by the CIT Bioethics Committee (IACUC). Female mice aged 2.5-3.0 months were used.

\subsection{MIC Evaluation}

In vitro MIC for each compound under study was determined using a conventional method described previously [16]. Briefly, each inoculum containing $500 \mathrm{H} 37 \mathrm{Rv}$ mycobacteria was cultured in the Dubos broth in a well of the round-bottom 96-well plate for 2 days at $37^{\circ} \mathrm{C}, 5 \% \mathrm{CO}_{2}$. Each compound from a stock solution ( $4 \mathrm{mg} / \mathrm{mL}$ DMSO) was serially 1.3-fold diluted in Dubos broth and added to mycobacterial cultures at gradually declining concentrations, with the final $0.1 \%$ DMSO concentration (separate experiments demonstrated no anti-mycobacterial activity of DMSO at concentrations $<2 \%$ ). Plates were additionally incubated for 14 days and examined for visible mycobacterial growth on the bottom of the well. MIC was defined as the range between the lowest drug concentration completely abrogating mycobacterial growth and the highest concentration at which the growth was discerned $[7,17,18]$. All samples were tested twice in triplicates.

MIC for intra-macrophage mycobacteria: Peptone-elicited peritoneal macrophages from B6 mice were obtained and purified as described earlier in detail [19]. $5 \times 10^{4}$ peritoneal macrophages were plated in wells of flat-bottom 96-well plates (Costar-Corning) in antibiotic-free RPMI-1640 medium supplemented with $10 \mathrm{mM}$ HEPES buffer, 5\% heat-inactivated fetal calf serum (FCS) and $2 \mathrm{mM}$ L-glutamine. Cells were allowed to adhere for $2 \mathrm{~h}$ at $37^{\circ} \mathrm{C}$ and $5 \% \mathrm{CO}_{2}$ and thereafter infected with $M$. tuberculosis $\mathrm{H} 37 \mathrm{Rv}$ at the $\mathrm{MOI}=5$ and incubated for $24 \mathrm{~h}$. To remove extracellular mycobacteria, culture medium was aspirated, the wells rinsed once with $37^{\circ} \mathrm{C}$-heated PBS and $0.2 \mathrm{~mL}$ of fresh supplemented RPMI-1640 medium added. Titrated compounds were added in triplicates of each concentration for another $48 \mathrm{~h}$ of culturing.

Cultural supernatants were aspirated, the wells rinsed once with warm PBS, and monolayers lysed with $0.1 \mathrm{~mL} \mathrm{H}_{2} \mathrm{O}$ for $10 \mathrm{~min}$ at room temperature. After restoring ionic balance with $0.1 \mathrm{~mL}$ of $2 \times$ Dubos broth, mycobacteria released from macrophages were incubated at $37^{\circ} \mathrm{C}, 5 \% \mathrm{CO}_{2}$ for $90 \mathrm{~h}$. $2 \mu \mathrm{Ci}$ of $\left[{ }^{3} \mathrm{H}\right]$-uracil (Isotope, St. Petersburg, Russia) per well was added for the last $18 \mathrm{~h}$. $\left[{ }^{3} \mathrm{H}\right]$-uracil uptake by mycobacteria was measured using Wallac 1409 liquid scintillation counter (Turku, Finland). As demonstrated earlier, parallel estimations of mycobacterial CFU counts and $\left[{ }^{3} \mathrm{H}\right]$-uracil uptake under identical culture conditions provided coefficients of correlation $>0.95$ [19]. MIC was defined as the lowest concentration of a compound providing $99 \%$ inhibition of $\left[{ }^{3} \mathrm{H}\right]$-uracil incorporation, compared to the drug-free control wells.

\subsection{Serum and Lung Supernatant Inhibition Assay}

Female B6 mice were injected intravenously with $5 \mathrm{mg} / \mathrm{kg}$ of TU112 in $0.2 \mathrm{~mL}$ of the water solution of alpha-tocopheryl polyethylene glycol 1000 succinate (TPGS), prepared as previously described [20,21]. At periods of $15 \mathrm{~min}, 1 \mathrm{~h}$ and $4 \mathrm{~h}$ after inoculation, blood samples were collected, 
and sera samples prepared and stored at $-80{ }^{\circ} \mathrm{C}$ in $100 \mu \mathrm{L}$ aliquots. Serum samples from mice that received $25 \mathrm{mg} / \mathrm{kg}$ INH and from intact mice served as controls.

To obtain lung tissue samples, $75 \mathrm{mg}$ of TU112 was dissolved in $10 \mathrm{~mL}$ of TPGS and put into a nebulizer. Mice were put in a $4000 \mathrm{~cm}^{3}$ chamber, and TU112 solution was sprayed for $1 \mathrm{~h}$. Mouse lungs were extracted, homogenized in $2 \mathrm{~mL}$ of Dubos medium and centrifuged at $2000 \mathrm{~g}$. Supernatants were collected, sterilized by filtration through $2 \mu \mathrm{m}$ filters, and stored at $-80^{\circ} \mathrm{C}$ in $100 \mu \mathrm{L}$ aliquots.

To assess anti-mycobacterial activity of serum and lung tissue samples, $100 \mu \mathrm{L}$ of $M$. tuberculosis culture in Dubos medium $\left(10^{4} \mathrm{CFU} / \mathrm{mL}\right)$ was put in the wells of a 96-well plate. $100 \mu \mathrm{L}$ of serum and supernatant samples was added to the first well, and serial 2-fold dilutions were prepared in triplicates. Plates were incubated in a $\mathrm{CO}_{2}$ incubator for 2 weeks, and anti-mycobacterial activity was determined as a visual lack of growth. Five female mice were used for each time point.

Author Contributions: Conceptualization: K.B.M., V.S.V., B.V.N.; methodology: K.B.M., V.S.V.; investigation: K.B.M., B.V.N., P.Y.I., L.N.T.; original draft preparation: K.B.N., A.S.A.; writing, review and editing: A.S.A. All authors have read and agreed to the published version of the manuscript.

Funding: This research was funded by the Federal budget, theme AAAA-A16-116032560061-9.

Conflicts of Interest: The authors declare no conflict of interest.

\section{References}

1. Hoagland, D.; Liu, J.; Lee, R.B.; Lee, R.E. New agents for the treatment of drug-resistant Mycobacterium tuberculosis. Adv. Drug Deliv. Rev. 2016, 102, 55-72. [CrossRef] [PubMed]

2. Quan, D.; Nagalingam, G.; Payne, R.; Triccas, J.A. New tuberculosis drug leads from naturally occurring compounds. Int. J. Infect. Dis. 2017, 56, 212-220. [CrossRef] [PubMed]

3. Wellington, S.; Hung, D.T. The expanding diversity of Mycobacterium tuberculosis drug targets. ACS Infect. Dis. 2018, 4, 696-714. [CrossRef] [PubMed]

4. Nunes, J.E.S.; Duque, M.A.; de Freitas, T.F.; Galina, L.; Timmers, L.F.S.M.; Bizarro, C.V.; Machado, P.; Basso, L.A.; Ducati, R.G. Mycobacterium tuberculosis shikimate pathway enzymes as targets for the rational design of anti-tuberculosis drugs. Molecules 2020, 25, 1259. [CrossRef]

5. Miggiano, R.; Morrone, C.; Rossi, F.; Rizzi, M. Targeting genome integrity in Mycobacterium tuberculosis: From nucleotide synthesis to DNA replication and repair. Molecules 2020, 25, 1205. [CrossRef]

6. Kadura, S.; King, N.; Nakhoul, M.; Zhu, H.; Theron, G.; Köser, C.U.; Farhat, M. Systematic review of mutations associated with resistance to the new and repurposed Mycobacterium tuberculosis drugs bedaquiline, clofazimine, linezolid, delamanid and pretomanid. J. Antimicrob. Chemother. 2020, dkaa136. [CrossRef]

7. Nikonenko, B.V.; Kornienko, A.; Majorov, K.; Ivanov, P.; Kondratieva, T.; Korotetskaya, M.; Apt, A.S.; Salina, E.; Velezheva, V. In Vitro Activity of 3-Triazeneindoles against Mycobacterium tuberculosis and Mycobacterium avium. Antimicrob. Agents Chemother. 2016, 60, 6422-6424. [CrossRef]

8. Velezheva, V.; Brennan, P.; Ivanov, P.; Kornienko, A.; Lyubimov, S.; Kazarian, K.; Nikonenko, B.; Majorov, K.; Apt, A. Synthesis and antituberculosis activity of indole-pyridine derived hydrazides, hydrazide-hydrazones, and thiosemicarbazones. Bioorg. Med. Chem. Lett. 2016, 26, 978-985. [CrossRef]

9. Orme, I. Tuberculosis drug screening program. Search for new drugs for treatment of tuberculosis. Antimicrob. Agents Chemother. 2001, 45, 1943-1946. [CrossRef]

10. Rautio, J.; Kumpulainen, H.; Heimbach, T.; Oliyai, R.; Oh, D.; Järvinen, T.; Savolainen, J. Prodrugs: Design and clinical applications. Nat. Rev. Drug Discov. 2008, 7, 255-270. [CrossRef] [PubMed]

11. Onajole, O.K.; Pieroni, M.; Tipparaju, S.K.; Lun, S.; Stec, J.; Chen, G.; Gunosewoyo, H.; Guo, H.; Ammerman, N.C.; Bishai, W.R.; et al. Preliminary structure-activity relationships and biological evaluation of novel antitubercular indolecarboxamide derivatives against drug-susceptible and drug-resistant Mycobacterium tuberculosis strains. J. Med. Chem. 2013, 56, 4093-4103. [CrossRef] [PubMed]

12. Simakov, S.V.; Velezheva, V.S.; Kozik, T.A.; Ershova, Y.A.; Chernov, V.A.; Suvorov, N.N. Synthesis and antitumor activity of some 4-oxo-1,2,3-triazino[5,6-b]indoles and 1,1-dialkyl-3-[indol-3-yl]triazenes. Pharm. Chem. J. 1983, 17, 707-712. [CrossRef] 
13. Nesterova, I.N.; Velezheva, V.S.; Alekseeva, L.M.; Padeiskaya, E.N.; Radkevich, T.P.; Baklanova, O.V.; Golovanova, E.A. Synthesis and antibacterial ctivity of 3-substituted-5H-4-oxo-1,2,3-triazino[5,4-b]indoles and 1,1-dialkyl(1-aryl)-3-(2-ethoxycarbonylindol-3-yl)triazenes. Pharm. Chem. J. 1990, 24, 813-817. [CrossRef]

14. Jayadevappa, A.; Mahadevan, H.; Hulikal, K.M.V. Efficient Synthesis of 2-Ethoxycarbonyl Indoles. Synth. Commun. 2009, 39, 2505-2515. [CrossRef]

15. Lyadova, I.V.; Eruslanov, E.B.; Khaidukov, S.V.; Yeremeev, V.V.; Majorov, K.B.; Pichugin, A.V.; Nikonenko, B.V.; Kondratieva, T.K.; Apt, A.S. Comparative analysis of T lymphocytes recovered from the lungs of mice genetically susceptible, resistant and hyper-resistant to Mycobacterium tuberculosis-triggered disease. J. Immunol. 2000, 165, 5921-5931. [CrossRef]

16. Yajko, D.M.; Nassos, P.S.; Hadley, W.K. Broth microdilution testing on susceptibilities to 30 antimicrobial agents of Mycobacterium avium strains from patients with acquired immune deficiency syndrome. Antimicrob. Agents Chemother. 1987, 31, 1579-1584. [CrossRef] [PubMed]

17. Dubuisson, T.; Bogatcheva, E.; Krishnan, M.Y.; Collins, M.T.; Einck, L.; Nacy, C.A.; Reddy, V.M. In vitro antimicrobial activities of capuramycin analogues against non-tuberculous mycobacteria. J. Antimicrob. Chemother. 2010, 65, 2590-2597. [CrossRef]

18. Bogatcheva, E.; Hanrahan, C.; Nikonenko, B.; de los Santos, G.; Reddy, V.; Chen, P.; Barbosa, F.; Einck, L.; Nacy, C.; Protopopova, M. Identification of SQ609 as a lead compound from a library of dipiperidines. Bioorg. Med. Chem. Lett. 2011, 21, 5353-5357. [CrossRef]

19. Majorov, K.B.; Lyadova, I.V.; Kondratieva, T.K.; Eruslanov, E.B.; Rubakova, E.I.; Orlova, M.O.; Mischenko, V.V.; Apt, A.S. Different innate ability of I/St and A/Sn mice to combat virulent Mycobacterium tuberculosis: Phenotypes expressed in lung and extra-pulmonary macrophages. Infect. Immun. 2003, 71, 697-707. [CrossRef]

20. Nikonenko, B.V.; Samala, R.; Einck, L.; Nacy, C.A. Rapid, simple in vivo screen for new drugs active against Mycobacterium tuberculosis. Antimicrob. Agents Chemother. 2004, 48, 4550-4555. [CrossRef]

21. Nikonenko, B.V.; Reddy, V.M.; Protopopova, M.; Bogatcheva, E.; Einck, L.; Nacy, C.A. Activity of SQ641, a capuramycin analog, in a murine model of tuberculosis. Antimicrob. Agents Chemother. 2009, 53, 3138-3139. [CrossRef] [PubMed]

(C) 2020 by the authors. Licensee MDPI, Basel, Switzerland. This article is an open access article distributed under the terms and conditions of the Creative Commons Attribution (CC BY) license (http://creativecommons.org/licenses/by/4.0/). 